\title{
Native Songs and Dances: Southeast Asia in a Greater Chinese Sporting Community, 1920-48
}

\author{
ANDREW MORRIS \\ Colgate University
}

China boasts a rich history of physical culture - from the archery of Confucian scholarly culture, to the kickball games used in military training, to aristocratic polo and golf games, to ice skating pageants performed for imperial audiences, to the storied and diverse Chinese martial arts. However, the modern physical culture introduced to China in the late nineteenth century through Japanese and Anglo-American channels represented a clean break from these previous modes of physical endeavour. Where older Chinese genres were laced with values of martial manhood or aristocratic privilege, the modern physical culture known as tiyu (体育) (literally, “body-cultivation") was a systematic ideology invested with definite ideals of the relationship between the individual and national bodies, and thus must be treated as a new and separate question. Sports and physical culture - physical education, callisthenics with a military flavour, recreation, physical fitness, all included in the broad term tiyu - were closely connected to notions of the nation, modernity and a modern citizenry. Beginning in the last years of the Qing Dynasty (1644-1911) and continuing through the period of the Republic of China (191249), the realm of physical culture served as an important conduit for teaching and learning about modernity, the nation, and the duties of the modern citizen.

By the 1920 s both modern sports and martial arts (wushu 武术) were commonly viewed as important modes of strengthening and modernizing a Chinese nation and race for the twentieth century. Tiyu-minded Chinese citizens also extended these considerations of physical culture, modernity and national strength to the so-called "Huaqiao (华侨)", or "Overseas Chinese" population in Southeast Asia. To many, these Nanyang (South Seas) Chinese' represented a tantalizing link to a potential "Greater China" that could transcend the borders of the troubled Republic, battle-scarred by the seemingly endless warlord fighting that plagued the new nation over the first fifteen years of its existence. Experts and planners in the world of Chinese physical culture hoped to use that realm to create a sporting version of this Greater Chinese community, where the scientific, educational, vigorous and virile motions of modern sport and physical culture could provide a valuable link between Chinese in China and their long-lost sojourner brothers and sisters.

'My use of these terms "Huaqiao" ("Overseas Chinese"), Southeast Asian Chinese, and Nanyang (South Seas) Chinese is not absolutely interchangeable. As Wang Gungwu has pointed out, the majority of Chinese in Southeast Asia, while identifying themselves as ethnically "Hua" (Chinese), do not call themselves "Huaqiao". Wang Gungwu, "Political Chinese: Their Contribution to Modern Southeast Asian History", in Wang Gungwu, China and the China Overseas (Singapore: Times Academic Press, 1991), p. 142. This term "Huaqiao" carries a decidedly statist flavour, one which resonates much more with official Guomindang or PRC nationalism than it does with the complicated identities of the Southeast Asian Chinese. Therefore, I use this term only to reflect this official nationalistic view or fantasy of Southeast Asian Chinese as forever loyal to the Chinese state. 
This article will discuss these Republican-era imaginings of a Greater Chinese sporting community - imaginings which can tell us much about Chinese notions of physical culture and of this elusive Overseas Chinese population during the 1920 s through the 1940s. It is not a study of Nanyang Chinese physical culture in and of itself - an interesting topic but one that is well beyond the scope of this research. Rather, the point of the study is to understand the significance attached by Republican Chinese to "Huaqiao" participation in the Chinese tiyu world. The period under consideration begins in 1920 , when a private Shanghai-based organization called the Pure Martial Athletic Association (Jingwu Tiyuhui) began spreading its famed martial arts among the Nanyang Chinese population. It ends in 1948, when several Southeast Asian Chinese communities sent athletes to join in China's Seventh National Games, a competition modeled upon (and held in preparation for) the Olympics.

The article thus explores two Chinese physical culture forms that were distinct yet equally valid modes of shaping and sharpening Chinese bodies and minds. Different forms of this modern tiy $u$ presented differing ideals of how a strong and modern nation would be made. Modern martial arts, brought to Southeast Asia purely and explicitly in the context of "Chinese culture", were understood to bring out in their practitioners a "national essence" of ancient and timeless Chinese virtues. The ideology of competitive sports, along which lines the Guomindang tried to recast its dreams of a territoriallydefined Chinese super-nation, was meant to provide for a healthy and self-conscious citizenry which, after proper training, could begin to work and play together as a team.

The overriding idea of these physical culture forms was in many ways the same: the new Greater China would be based in new transnational communities of healthy and modern Chinese people, practised in self-discipline and ever attentive to the larger consequences of all their actions and movements. This awareness of the body - and specifically its potential for national triumph or disaster - could only be taught through a physical education, through a tiyu "body-cultivation". Yet the fork at which these models diverged was crucial. Would modern physical culture be an agent of a new, robust and proud Chinese culture, or of a powerful and expansive Chinese nation-state?

\section{China and a Sporting Southeast Asia}

The rapid success of the tiy $u$ ideology in early Republican China can be traced to the participation and influence of ethnic Chinese athletes visiting or returning to their ancestral homeland from Hawaii, Japan, Europe and North America. The modern sporting culture came to China via the powerful nations of the globe, and it is logical that the Overseas Chinese populations in these nations would serve as one conduit of this culture. ${ }^{2}$ The participation in the domestic Chinese tiyu world by these sons and daughters of Han now

${ }^{2}$ On the Hawaiian Chinese influence on physical culture at St. John's University in Shanghai, see St. John's University 1879-1929 (Shanghai: St. John's University Alumni Association, 1929, Taipei reprint 1972), pp. 58-59. On the Honolulu Chinese Base Ball Team that joined the 1914 National Games at Beijing and the 1915 Far Eastern Championship Games at Shanghai, see "The Athletes of China", China's Young Men 11,10 (1916): 526; Chen Xianming, Liang Youde and Du Kehe, Zhongguo bangqiu yundongshi [The history of baseball in China] (Wuhan: Wuhan chubanshe, 1990), p. 11: J. Wong-Quincey, "The Far Eastern Championship Games", China's Young Men 10,10 (1915): 429. 
residing in modern settings like Japan or the West lent an authenticating touch of Occidentalism to the Chinese sporting scene, while also helping to consolidate the connections between these sporting practices and notions of a new China.

Yet the Chinese living in the colonies of Southeast Asia, particularly those in the Philippines, British Malaya and the Dutch Indies, were seen as forming the most important foundation of this diverse overseas sporting world. Since the late Qing Dynasty, many had looked to these particular Chinese sojourners to contribute their share to the motherland. Such contributions would also serve to create bridges between a territorial Chinese state and Nanyang lands seen, in Victor Purcell's words, as terra irredenta. ${ }^{3}$ The "Song of Revolution", possibly written by anti-Manchu scholar Zhang Binglin, hinted that Huagiao contributions to a Chinese republican revolution could "re-sinicize" these sojourners so far from the soul of their racial community. Perhaps more pragmatically, it also could solidify Chinese claims and statuses in Southeast Asia so that there, "the Westerners [would] retreat to call you brothers". 4

The sporting connections between a geographical China and Nanyang Chinese go back to the late Qing period as well. Overseas Chinese returning from Southeast Asia to their ancestral homes (especially in Meixian County, Guangdong) brought back rubber soccer balls and a zest for the game of soccer learned in the colonies. In Meixian, if not in other areas, the game caught on so rapidly that by the end of the Qing, soccer was part of the curriculum of every elementary school in the county. ${ }^{5}$ Others have seen a similar debt to returning athletically-inclined sojourners in the development of Taishan County,

On the influence of an Overseas Chinese sporting community in Japan, see Wu Wenzhong, Zhongguo jin bai nian tiyu shi [The history of Chinese physical culture over the last century] (Taibei: Taiwan shangwu yinshuguan, 1967), p. 95; Ruan Weicun, Fuandong yundonghui lishi yu chengji [History and Records of the Far Eastern Championship Games] (Shanghai: Qinfen shuju, 1933), p. 81; Andrew Morris, "Cultivating the National Body: A History of Physical Culture in Republican China" (Ph.D. diss., University of California, San Diego, 1998), pp. 228-29.

On Chen Hanqiang, an ex-European light middleweight title belt who coached the great Zheng "The Oriental Cobra" Jichang and the 1936 Chinese Olympic boxing team, see Zhou Shibin, "Yidai quanji zongshi - Zheng Jichang" [Zheng Jichang, boxing master of his day]. Shanghai tiyu shihug 29 (1990): 21; Chuxi Di shiyi jie Shijie yundonghui Zhonghua daibiaotuan baogao (Official Report of the Chinese Delegation to the XIth Olympiad, Berlin, 1936) (Shanghai: Zhonghua quanguo tiyu xiejinhui, 1937), Section 1, p. 10.

On Chopper Wong, the Chicago-born "Heavyweight Wrestling Champion of the Orient", see "The Future of Wrestling (Editorial)", The Illustrated Week-End Sporting World (Jingle huabao) 11,4 (1937): 3-4; "Wuguo shuaijiao mingiang Huang Bochang xiaozhuan" [Short biography of our nation's star wrestler Huang Bochang], Qinfen tiyu yuebao (The Chin Fen Sports Monthly) 4,5 (1937): 392 .

${ }^{3}$ Victor Purcell, The Chinese in Southeast Asia, second edition (London: Oxford University Press, 1965), p. 300.

${ }^{4}$ Wang Gungwu, "The Origins of Hua-Ch'iao", in Wang Gungwu, Community and Nation: China, Southeast Asia and Australia (Kensington, Australia: Asian Studies Association of Australia, 1992), pp. 7, 10.

${ }^{5} \mathrm{Li}$ Cimin, "Meixian zuqiu yundong shihua" [Stories from the history of the soccer movement in Meixian County], in Guangzhou wenshi ziliao xuanji, di ershisi ji [Selected materials on the history of Guangzhou, Vol. 24] (Guangzhou: Wenshi ziliao yanjiu weiyuanhui, 1981), pp. 164-65; Li Cunzhang, "Haiwai chizi yu zuqiu zhi xiang Meixian" [China's overseas subjects and Meixian County, the home of soccer], Tiyu wenshi 40 (1989): 50. 
Guangdong, as the volleyball capital of China. ${ }^{6}$ By 1910, Jiaoyu zazhi (The Chinese Educational Review) was printing photos of Overseas Chinese physical culture endeavours, a military drill exercise conducted at the Chinese (Zhonghua 中华) Academy in Java?

In the early Republican period, Chinese were able to learn much about physical culture in Southeast Asia. For example, the American-designed physical education programmes in the Philippines were widely admired in China as healthy and rational formulae by which to reform Filipino social and marriage customs, advance the cause of education, and strengthen Filipino bodies. ${ }^{8}$ Sports also could present a perfect space for Nanyang Chinese to show their support for China's revolution. In the fall of 1912, Shanghai's The True Record pictorial magazine published a photograph of an athletic meet held in Sandakan to commemorate the first anniversary of the Wuchang Uprising that sparked the 1911 Revolution. And at the 1921 Fujian Provincial Interscholastic Games, among the prizes for outstanding participants were six silver cups donated by the Philippine university administration and Chinese student union, the Chinese-owned Benevolent Longevity Insurance Company, and Chinese-owned lumber, textile and oil factories in Manila. ${ }^{10}$

Modern physical culture, a politically and culturally viable realm in both colonial Southeast Asia and early Republican China, was certainly burdened with far different significances in these different settings. The model of sports as a purely colonialist enterprise undertaken by the European powers in Southeast Asia looked very different from the evolving indigenous structures supporting this modern sports culture in China. Yet this world of tiyu, and the national and international worlds to which it could link its participants, represented to many a common ground between the Republic of China and these communities scattered throughout the South Seas colonies.

\section{The Pure Martial and Its Overseas Expansion}

The first Chinese organization to make this daring connection to Overseas Chinese communities was the Pure Martial Athletic Association (Jingwu Tiyuhui 䊉武体育会) of Shanghai. " The genealogy of the famed Association, originally established in 1910 as the Pure Martial Calisthenics \& Drill School (Jingwu Ticao Xuexiao 精武体操学校), is wellknown among martial arts enthusiasts today. Martial arts expert Huo Yuanjia left Tianjin

\footnotetext{
${ }^{6}$ Madeline Hsu, personal communication.

${ }^{7}$ Jiaoyu zazhi (The Chinese Educational Review) 2,7 (1910): 1858. From 1909 to 1922, Jiaoyu zazhi printed 203 physical culture-related photographs, 14 of which were of Overseas Chinese tiyu participants in Southeast Asia. Hsu Yuan-ming, "Jiaoyu zazhi tiyu zhaopian neirong fenxi (19091937)" [An analysis of physical culture-related photographs in The Chinese Educational Review (1909-1937)], unpublished paper (1995), p. 35.

${ }^{8}$ Jiang Weiqiao, "Feilubin zhi tiyu" [Physical culture in the Philippines], Jiaoyu zazhi 9,4 (1917): 79-82; Qian Zhixiu, "Tiyu jiangyi (xu)" [Lectures on physical culture (continued)], Jiaoyu zazhi 7.3 (1915): 26-27.

9"Nanfang zhi Guoqingri (Celebration of the anniversary of the Revolution in the South)". Zhenxiang huabao (The True Record) 1,10 (1912).

${ }^{10}$ Fujian quansheng xuexiao lianhe yundong dahui baogao [Official Report of the Fujian Provincial Interscholastic Games] (Fuzhou: Fujian jiaoyuting, 1921), pp. 105-114.

"The Jingwu's own English translation was "Chin Woo Athletic Association". However, I prefer to translate "Jingwu" into English, "Pure Martial" hopefully capturing this notion of their martial arts as the purest and most essential of China's martial tradition.
} 
in 1907 for Shanghai, where he quickly became renowned for his penchant for flattening Japanese ronin, Russian rascals, and other foreign rogues in general. In 1910, the Jingwu was founded, according to nationalist narratives, with the assistance of Revolutionary Alliance figures Chen Qimei and Song Jiaoren. ${ }^{12}$ Regardless of how much of the Jingwu creation myth one believes, the founding of the Pure Martial School truly did mark the beginning of a new era for China's indigenous martial arts.

Some years after its founding by the northern wushu master Huo, the Pure Martial came under the control of several wealthy and connected Cantonese merchant-martial artists in Shanghai. Starting around 1916, these Jingwu captains worked to expand its martial arts media presence. (This public relations enterprise began, impressively enough, with a tense sparring match with the iconoclastic literary giant and martial arts opponent Lu Xun in the editorial pages of New Youth $!^{13}$ ) The Association tried to appeal to urban Chinese women as an organization committed to gender equality. Jingwu managers solidified a modern public image by creating and strengthening ties to political and commercial elites in Shanghai and Guangzhou. The success of these agendas enabled its leaders to completely transform the Pure Martial from a narrowly defined provincial martial arts school into a modern urban agent disseminating scientized and nationalized Chinese martial arts. ${ }^{14}$ The martial arts of the new Jingwu could no longer be dismissed as stagnant superstitious rituals practised by the Chinese peasantry of the imperial past - a common charge ever since the Boxer Uprising of 1900. In a modern world, in a modern economy, these arts would have to become a nationalized, commercialized force in their own right.

Another important element of the Jingwu's appeal throughout China - ultimately allowing it to reach a peak of fifty-two branch organizations - was its work to spread martial arts beyond the borders of the Republic, to a Greater China that included millions of sojourners in Southeast Asia. This extension south to the Chinese of Malaya, Indonesia, Cambodia, Vietnam and Siam was instrumental in creating the powerful image of the Pure Martial as a repository of the truly Chinese arts and skills, capable of transcending Republican borders and advancing along the courses of the Cantonese and Hokkien diasporas in Southeast Asia.

${ }^{12}$ The final impetus to start the organization supposedly came when Huo's star pupil Liu Zhensheng was able to scare away a barnstorming foreign muscleman who was stirring up trouble in Shanghai's brothels and other dens of vice, publicly claiming that the whole of China could provide no competition for his strength and fighting abilities, and pledging to "flatten any Sick Man of East Asia" who dared challenge him. The foreign knave was either Russian or English, depending on which version of the story one hears. Kuang Wennan and Hu Xiaoming, Zhongguo tiyu shihua [Items from the history of Chinese athletics] (Chengdu: Badu shushe, 1989), p. 219; Wu Wenzhong, Zhongguo jin bai nian, p. 40; Jiang Zhihe, "Aiguo de Jingwu tiyuhui" [The patriotic Pure Martial Athletic Association], Shanghai tiyu shihua 30 (1991): 36; Han Xizeng, "Jianping Chen Yingshi faqi chuangban Jingwuhui" [A brief evaluation of Chen Yingshi's role in launching and founding the Pure Martial School], Shanghai tiyu shihua 29 (1990): 32.

13"Quanshu yu quanfei" [Boxing and Boxer bandits], Xin qingnian (La Jeunesse) 6,2 (1919): 218-21. This exchange is also described in Morris, "Cultivating the National Body", pp. 450-52, and Paul A. Cohen, "The Contested Past: The Boxers as History and Myth", Journal of Asian Studies 51,1 (1992): 84-87.

${ }^{14}$ Morris, "Cultivating the National Body", pp. 441-65. 
This Nanyang Chinese presence provided a golden opportunity for the savvy businessmen now in charge of this once-Pure Martial system, as will be discussed below. But this enigmatic Overseas Chinese population also represented an important challenge to the bearers of these wushu traditions. By the early $1920 \mathrm{~s}$, it was clear that the unfortunate and ugly political trends in the new Chinese Republic had failed to rouse these Huaqiao from their pragmatic loyalties to their adopted Nanyang homes. The Pure Martial expansion into Southeast Asia gambled that the cultural traditions embodied in these ancient (yet safely modernized) martial arts would succeed in reuniting these sojourners with their motherland in a new cultural Greater China. Physical culture connections between the ROC and Nanyang Chinese continued throughout the Republican period, but the Pure Martial model developed in the early 1920 s represents this notion of culture as the most logical basis for a Greater China in these messy political times.

Not only did the Jingwu extension to Southeast Asia fit seamlessly with Chinese imaginations of a transcendent and culturally-defined China, but the Pure Martial project also came at just the right time to capture the interests of the Nanyang Chinese population. Its formula of enlightened martial arts and clean modern living - so unique and totalizing that members felt comfortable referring to their doctrine as "Jingwu-ism"(Jingwuzhuyi 武主义) $)^{15}$ - encompassed many values that suited the needs of these Southeast Asian Chinese as well. Wang Gungwu, in his work on the "limits of Nanyang Chinese nationalism" in the 1920 s, has written on this group's growing dismay at the disturbing fate of the Republic. He identifies a decided turn from pro-Republican nationalism toward an understanding of Chinese identity based in the very real problems of their treatment in the colonies where they now planned their futures. ${ }^{16}$ However, brightening these futures, and the futures of their children, would require more than just the "sound modern Chinese education" that Wang cites. Many of these Nanyang Chinese were quickly attracted to the promises held within the modernized martial arts brought to their homes by the eager proselytizing agents of the Pure Martial.

The Jingwu's expansion into Southeast Asia began in 1919, when the appropriatelynamed Huang Qiangya ("Qiangya" 强亚 meaning "Strong Asia"), a Shanghai reporter and key Pure Martial member, went to work for the Chinese Mutual Benefit Times (Yiqumbao 羊群报) in Kuala Lumpur. Huang soon found there a group of Overseas Chinese youth who enjoyed practising martial arts with him. It was not long before Luo Xiao'ao, Director of the Guangzhou Pure Martial Association, travelled to the Malayan Peninsula, teaching martial arts and spreading the Jingwu word. ${ }^{17}$ Calculations of this Nanyang market paid off, and the Malayan Chinese could not get enough. Their letters poured into the offices of the Central Jingwu in Shanghai, requesting copies of the Pure Martial Constitution and regulations, and asking that representatives be sent to help found Association branches in these Overseas Chinese communities.

${ }^{15}$ Lu Weichang, "Zhongguo wushu zhi jianglai" [The future of Chinese martial arts], in Di san ci quanguo yundong dahui tekan [Special publication of the Third National Games] (Hankou: Hankou jidujiao gingnianhui, 1924).

${ }^{16}$ Wang Gungwu, "The Limits of Nanyang Chinese Nationalism, 1912-1937", in Wang Gungwu, Community and Nation, p. 50.

${ }^{17}$ Yu Jue'an, "Jingwu nan chuan jiqi fazhan zhi chutan" [A preliminary inquiry into the Pure Martial Association's southern spread and development], Shanghai tiyu shihua 30 (1991): 41. 
This amazing demand gave rise to the celebrated trip of the "Five Special Ambassadors" - five of the Jingwu's top names, including Luo, Shanghai leader Chen Gongzhe and Shanghai Women's director Chen Shichao - to the Nanyang in the summer of 1920 , visiting Malaya, the Indies and Indochina. Besides their valuable wushu know-how, the Ambassadors took with them more than 3000 feet of Pure Martial film to assist them in passing on what they called their "national-essence calisthenics" (guocui ticao 国粹体 操). Their cargo also included bundles of Pure Martial publications to sell to their bourgeois patrons in Nanyang. ${ }^{18}$ These money-making possibilities involving the new martial arts could also be turned toward nationalist ends. The highlight of the trip was a two-night benefit performance given by the Ambassadors before some 10,000 spectators in Singapore, with proceeds going to aid flood victims in China. ${ }^{19}$ The counselling and coaching of the Ambassadors was so appreciated that the more enthusiastic local Chinese supporters offered their homes and gardens as office and exercise space. By 1921, four branches were operating in British Malaya - Selangor, Singapore and Kampar Associations, and a Selangor Women's Jingwu. ${ }^{20}$ And as one might expect, Chinese business elites in each of these locales - like banking magnate Li Tiecen or Singapore Chinese Chamber of Commerce leader Lin Tuiqian - were the most visible of the Jingwu's supporters. ${ }^{21}$

Wang Gungwu has described the colonial "counter-nationalist forces" at work in areas where Nanyang Chinese were most numerous and the measures taken to arrest the early 1920 s tides of nationalism in these colonies. ${ }^{22}$ He sees these trends leading to new choices by Overseas Chinese as to how they would maintain their identities as Chinese. Wang does not mention the Jingwu's martial arts invasion, but it is easy to see how these ultra-"Chinese" forms could serve as an important site for the creation of new, less partisan, yet fiercely and romantically loyal Chinese identities. In his work, Wang leaves academia as the only avenue for new Chinese nationalism, and labels the identities learned through Chinese newspapers and textbooks as "abstract and cerebral, taught ... but cut off from where the action was". ${ }^{23}$ The Overseas Chinese response to Pure Martial, however, allows us to move beyond Wang's model of a purely academic Nanyang nationalism. Instead, we see that in the cultural Chinese nationalism taught through the forms, gestures and traditions of the martial arts, these lucky new followers of the Jingwu way could not have been any more actively engaged in, or any closer to the action of, building a new transcendent Greater China.

Jingwu personnel quickly became as serious about their Southeast Asia operations as the Chinese there were about learning these prized arts. In the early 1920s, the Pure Martial proponents worked vigorously within China to found Jingwu branch organizations throughout the southern and central provinces. Still, the tremendous response from the

\footnotetext{
${ }^{18} \mathrm{Cai}$ Yangwu, "Jingwu shukan xi" [An analysis of Pure Martial Association publications], Shanghai tiyu shihua 29 (1990): 45; Zhou Peiyu, "Lun Jingwu nuijie" [On the heroines of the Pure Martial], Shanghai tiyu shihua 30 (1991): 34.

${ }^{19}$ Luo Xiao'ao, Jingwu waizhuan [An alternative history of the Pure Martial] (Shanghai: Jingwu tiyuhui, 1921), pp. 28-29.

${ }^{20} \mathrm{Yu}$ Jue'an, "Jingwu nan chuan", pp. 42-43.

${ }^{2 !}$ Ibid., p. 42.

${ }^{22}$ Wang Gungwu, "The Limits of Nanyang Chinese Nationalism", pp. 51-52.

${ }^{23}$ Ibid., pp, 53-54.
} 
Nanyang Chinese was even harder for the Pure Martial to resist. Huo Dong'ge, second son of Jingwu founder Huo Yuanjia, left his work at the Guangzhou branch in 1923 to take his teachings to Surabaya in the Indies. Supposedly able to converse in Cantonese after his stint in the Guangzhou Pure Martial structure, Huo soon created a kung-fu fever among Surabaya Chinese by teaching martial arts in local Chinese schools and holding public demonstrations of the "Huo Family Boxing" and "Eight Drunken Masters" styles. It is noteworthy that these public demonstrations were sponsored by the Nanyang Brothers Tobacco Company, the same firm whose persistent (and sometimes shameless) attempts to position themselves as an agent of Chinese nationalism, culture and morality in the 1910 s-20s have been richly documented by Sherman Cochran. ${ }^{24}$ How many cigarettes these exhibitions sold for the Nanyang Brothers is hard to say, but they did create an even more potent martial arts addiction among Surabaya Chinese. A Jingwu branch was founded there in 1924, followed by a similar success in Jakarta the next year.

During the $1920 \mathrm{~s}$, twenty-two other Jingwu missionaries (including three women) would be sent to spread wushu in the fertile Chinese communities of Malaya, the Indies, Cambodia and Siam. ${ }^{25}$ Some of these pioneering martial artists literally made this their life work. Li Zhixi, a graduate of the Cantonese-run Chongde Girls' Middle School in Shanghai, was sent to Kuala Lumpur in 1921 to teach martial arts at the new Selangor Jingwu Women's Branch Association. In 1923, she transferred to the Penang Association, where she was active until her death in $1990 !^{26}$ Wei Yuanfeng, heir to a long family martial tradition in Jingxian, Hebei, was invited at the age of sixteen to teach northern wushu styles at the Shanghai Pure Martial centre. In 1924, Wei was also sent to teach in branch organizations in Malaya; he remained there until his death in 1984. ${ }^{27}$ Thanks to dedicated teachers like these, each Nanyang Pure Martial branch, with its representatives of China's different martial traditions, could become another microcosm of the Chinese wushu nation that lay at the heart of the Jingwu project. ${ }^{28}$

From time to time Jingwu heavies from the Central Association in Shanghai would also venture to Southeast Asia to inspect local facilities and put on still more martial arts demonstrations for the adoring fans there. In December 1924, a Seremban crowd of some seven or eight hundred wushu aficionados packed the Yijing Movie Theater to welcome Jingwu messengers Lu Weichang and Luo Xiao'ao to town. Lu and Luo treated the audience to a demonstration of their skills, and also to Pure Martial films and a slide

\footnotetext{
${ }^{24}$ Sherman Cochran, Big Business in China: Sino-Foreign Rivalry in the Cigarette Industry, 1890-1930 (Cambridge: Harvard University Press, 1980), pp. 63-69, 109, 120-21, 178-85.

${ }^{25}$ Yu Jue'an, "Jingwu shiliao" [Historical materials on the Pure Martial Association], Shanghai tiyu shihua 24 (1989): 16-17.

${ }^{26}$ Yu Jue'an, "'Jingwu shengnu' - Li Zhixi" [Li Zhixi, heroine of the Pure Martial], Shanghai tiyu shihua 26 (1990): 56-57; Zhou Peiyu, "Lun Jingwu nüjie", p. 35.

${ }^{27}$ Yu Jue'an, "Jingwu nanxing liang xianfeng" [Two pioneers of the Pure Martial's southern expansion], Shanghai tiyu shihua 27 (1990): 40.

${ }^{28}$ As one might guess, imagined nation-ties were not the only connections operating here. The Jingwu branch in Haiphong (Tonkin) was housed on the premises of the Xinhui County (Guangdong) Native-Place Association, allowing us to see how regional loyalties were also an important aspect of the Pure Martial's push into Southeast Asia. Su Zhongwen, "Haifang Jingwu jinxun" [News from the Haiphong Pure Martial branch], Jingwu zazhi 46 (1924): 28.
} 
show as they explained the Jingwu's modernized martial arts. ${ }^{29}$ This particular Nanyang journey, also joined by Yao Chanbo, included 54 presentations just like the one in Seremban. When Lu and Yao returned to Shanghai, the Jingwu stalwarts held yet another meeting where they described conditions in several Southeast Asian branch organizations and tried to express to local personnel the great enthusiasm shared by the Nanyang Chinese for the Pure Martial. Perhaps the most telling anecdote related to precocious Chinese marketing schemes in Nanyang:

The two words "Pure Martial" [Jingwu]! One could say that they truly stir deep feelings within people there. In every locale in Southeast Asia, they love to use the Pure Martial emblem. So the businessmen there all add the two words "Pure Martial" to their goods - like Pure Martial hats, Pure Martial shoes, Pure Martial firecrackers, etc. Everyone seems to love it, and it is great for business too. ${ }^{30}$

The Jingwu's extension to the Overseas Chinese community in Southeast Asia speaks directly to another difference between martial arts and other modes of modern physical culture. ${ }^{31}$ The sports tiyu as learned from the West was all about the modern nation-state, with its emphasis on competition between nations, the accumulation of points and scores, its set and clearly defined spatial and temporal boundaries. Participation in modern sport was meant to recreate in every contest, for every participant, the experience of living and participating as a citizen in the modern nation-state. ${ }^{32}$ The Jingwu martial arts that its messengers brought to the Chinese of Southeast Asia shared none of these constraints. Joining in the Pure Martial's wushu allowed anyone, anywhere, the chance to re-learn what it was like to be Chinese. The techniques and movements of wushu, having survived Manchu prohibitions and Republican ridicule, were a perfect resilient match for the Nanyang Chinese, with their long and often thankless service to China from abroad, and the suffering they had endured. The martial arts, supposedly ancient and timeless, extended perfectly to this boundless imaginary called Greater China.

The Jingwu Athletic Association achieved its greatest currency throughout China and beyond in the first half of the 1920s, at the same time that Anglo-American sports were beginning to sweep across the consciousness of Chinese urban youth. Surprisingly, the anti-feudal, anti-traditional legacy of China's May Fourth Movement did little to slow the advance of the Pure Martial message. The Jingwu came to dominate the Chinese martial arts world during these years, thanks in part to policies which borrowed heavily from the Western-themed sports - namely, association with modern science and a literate citizenry, and cross-pollination with rising urban commercial forces. The Jingwu also explicitly

29."Ji Furong Jingwu huanyinghui" [On the Pure Martial welcoming party in Seremban], Jingwu zazhi 38 (1924): 64 .

${ }^{30}$ Jian Shijian, "Huanying Lu Yao liang zhuren huiguo ji" [On the welcome-home reception for Directors Lu and Yao], Jingwu zazhi 40 (1924): 59-64.

${ }^{31}$ The Jingwu were not the only Republican martial arts presence in Southeast Asia; also notable were the "South Fujian Martial Arts Squads" organized and taken to Malaya on fundraising tours by the Singapore-based Chinese business leader Tan Kah Kee in 1929 and 1930 . Hong Zhengfu, Lin Yinsheng and Su Yinghan, "Sanbai nian lai de Yongchun baihequan" [Yongchun's White Crane boxing over the last 300 years], Tiyu wenshi 19 (1986): 31-32.

${ }^{32}$ The Pure Martial also retained its dual emphasis on martial arts and Western-style sports in its Southeast Asia branches. In fact, the Manila Jingwu basketball team captured the 1928 Philippines basketball championship. Liangyou (The Young Companion) 24 (1928): 22. 
associated martial arts with modern sports, crediting the athletic activities its centres offered as the nutritious "rice and bread" which fuelled the movement's growth. ${ }^{33}$ In fact, one important moment for the Pure Martial movement in the 1920 s was the inclusion in China's 1924 National Games of martial arts (guocao 国操, literally "national calisthenics") demonstrations. Over three days, representatives from ten Wuhan-area schools and the men's and women's Jingwu branches from Hankou, Nanchang, and Kuala Lumpur performed 107 separate sets before the National Games crowds. ${ }^{34}$

Modern Chinese martial arts, especially the Jingwu brand, clearly owed much to the ideologies of sport that swept the late nineteenth- and early twentieth-century world. Yet the architects of the Jingwu were much more than mere imitators tracing Western trails to success, and their martial arts much more than just a uniquely Chinese "sport". The ancient traditions and bright promise that these new Chinese martial arts signified were clearly a different proposition from the modern sports pushed by the European colonial powers in Southeast Asia. If the Pure Martial borrowed practices and philosophies from missionary- and Chinese-run sporting programmes in China's cities, their project was also clearly blessed with the perfect connotations of, and connections to, a cultural Greater China.

The Pure Martial's energetic pursuit of a Nanyang Chinese following was a key element in their successful promotion of a wushu product long given up for dead by so many Chinese modernists. Their project also allows us to understand the power of a culturally-defined Greater China not tainted by or burdened with politically partisan connotations, but created and reproduced in each Jingwu branch or Nanyang Chinese home with every practised repetition of wushu traditions. ${ }^{35}$

\section{The Guomindang State and its Sporting "Huaqiao" Community}

The Guomindang (Nationalist Party) state, established at Nanjing in 1927, was the first totalizing and stable central government structure in the history of the Republic. The Guomindang (KMT) exercised total administrative control over only a few of China's central provinces, but its relatively solid financial and ideological base allowed the Nationalists finally to get down to the business of building a modern nation-state. Among the many cultural and political shifts that came with this new state were changes in Republican physical culture policy, and also in Chinese imaginations of the Nanyang lands and their Overseas Chinese residents.

One of the innovations of the new state was the explicit partisan politicization of Chinese tiyu. The new political context, and its extension to the political culture world, meant that the old "cultural China" model of the Pure Martial could no longer be acceptable. Nationalist physical culture could little afford such vagueness; now this tiyu realm would be directed toward building a united Chinese minzu (民族), or "nation-race". The official

${ }^{33}$ Zhong Ruiqiu, "Lun Jingwu tiyuhui yu Xin wenhua yundong" [On the Pure Martial Athletic Association and the New Culture Movement], Shanghai tiyu shihua 29 (1990): 40.

${ }^{34}$ Chen Tiesheng, "Di san jie quanguo yundonghui guocao jishi benmo" [A full account of the national calisthenics demonstration at the Third National Games], Jingwu zazhi 42 (1924): 6-8.

${ }^{35}$ It is perhaps a similar logic that sustains the Jingwu's popularity in Southeast Asia to this day; contemporary worldwide Jingwu rosters are still dominated by branches in Malaysia and Singapore. 
1930s physical culture agenda, followed by many educators loyal to the Guomindang, called for the creation of a "physical culture for the masses", where proper, scientific physical training would allow all Chinese to become efficient members of the production force and of the new muscular "minzu (national-racial) body". Other hard-line KMT elements pushed for a new "militarized physical culture" curriculum designed along Italian and German lines.

Alongside these heavily politicized blueprints, however, was a more pragmatic emphasis on the conventional sports - soccer, basketball, track and field, tennis, and so on - on which the international sporting stage was founded. It was in this sporting space that new imaginations of a Southeast Asian Chinese sporting community were now based as well. The foci of this sports tiyu - teamwork and sportsmanship - should be understood as part and parcel of the nation-state ideology. Sports were self-consciously rational and modern with their measurements, times, physical and behavioural boundaries, rules and regulations; their myths of free movement and "natural" motions; and their celebration of modern masculine ideals. Sports provided the grounds for make-believe Darwinist struggles that would cultivate the competitive instinct so necessary for survival in the modern world. These sporting struggles would also condition the team's members for the ideologies of "friendly struggle" and "fair competition" under which the nation-state system and capitalism justified their tandem global expansion. From the late 1920 s on, China's sporting ties with the Nanyang Chinese wrer be conceived in this realm of competitive sport as an instrument of the modern Chinese nation-state.

The martial arts were still very privileged in the new Chinese state tiyu apparatus as valuable (if still, to some, embarrassingly superstitious and un-scientific) legacies of the "national essence". The Guomindang, eager to conscript this crucial genre for the Nationalist cause, loaded the category of martial arts with entirely new connotations of party and state. Martial arts, now known officially as the guoshu 国 $末$ or "national arts", were the recipient of generous state funds and were institutionalized in the Central Martial Arts Academy (Zhongyang Guoshuguan 中央国求馆) structure. Old Pure Martial connections paid off handsomely for this organization that took the Jingwu's place in the new Chinese order, as state funding was supplemented in 1928 by Overseas Chinese contributions totalling 250,000 yuan. ${ }^{36}$ However, the Guoshuguan's purely state orientation failed to captivate for long the martial arts-minded Chinese of Southeast Asia. Instead, the latter remained loyal to a Pure Martial organization which did not revolve about the Guomindang party-state, but rather operated through unofficial networks traversing the seas between Nanyang and Jingwu remnants in the coastal city of Xiamen. ${ }^{37}$ (Indeed, Southeast Asian Chinese have to this day remained the bread and butter of the Pure Martial Association; of thirty-five registered "Chin Woo" branches operating around the world in 1999, thirteen are located in these ASEAN nations, as opposed to just six in the PRC. ${ }^{38}$ )

\footnotetext{
${ }^{36} \mathrm{Lin}$ Boyuan, Zhongguo wushu shi [The history of Chinese martial arts] (Taibei: Wuzhou chubanshe, 1996), p. 448.

${ }^{37}$ Morris, "Cultivating the National Body", p. 481.

38."Western Australia Chin Woo Athletic Association Incorporated: Chin Woo - One Big Family", <http://www.chinwoo.com.au>.
} 
Notions of a sporting Greater China became dominated by ideologies of competitive sports, which, in many ways, made it easier to imagine actual "national" ties - by this point in the twentieth century, the only type that mattered - between the Republic and its long-lost overseas sojourners. Purcell identified a British "fear of a highly organized imperium in imperio" in their handling of the KMT presence in Malaya, where Nationalist agents worked to spread among local Chinese Sun Yat-sen's theory "that nationality followed the jus sanguinis and not jus soli". ${ }^{39}$ One may be tempted to see British concerns about Chinese nationalism and its destabilizing effects on colonial rule as smacking of paranoia. Yet we should keep in mind the real fervour with which loyal and patriotic KMT agents attempted to bring the great anti-imperialist struggle to the Nanyang Chinese, ${ }^{40}$ and how easily this assertiveness may have spilled into Greater Chinese visions of a new empire extending into the South Seas. ${ }^{41}$

These "national" ties could also be reproduced in the sporting world. Starting in the late 1920s, Southeast Asian Chinese were common participants in China's most crucial sporting events, from the National Games to the Far Eastern Championship Games and China's Olympic team. In 1927 Shanghai hosted the eighth meeting of the Far Eastern Championship Games, a (usually) biannual competition among Chinese, Japanese and Philippine Islands athletes. That summer, it was announced that the Chinese FECG team would include two outstanding Nanyang Chinese tennis players. Sports fans surely hoped that their help in defeating the powerful Japanese squad might somehow reflect on a strong and worthy Greater Chinese presence in Asia - yet very few people even seemed to know the names of these athletes. One Chinese source could only call them (in English) the "Cheong brothers" from Singapore, ${ }^{42}$ while another referred to them as "the Chinese tennis players who defeated the Aragon Brothers in Manila and who are now staying at Singapore" ${ }^{43}$ After arriving in Shanghai, the Indonesian Chinese stars Khoo Hooi-hye and Gordon Lum cleared up all questions about their identities by leading the Chinese tennis team to a victory over the Japanese and Filipino contingents. Their success also sparked a new trend of Southeast Asian "Huaqiao" participation in the Chinese national sporting scene.

By the 1930s, it was fully expected of ethnic Chinese athletes who excelled in their native Southeast Asian environments that they would show their true loyalty by joining the ROC sports squads. ${ }^{44}$ That they would prefer to represent the Republic of China rather than even their own native countries became common sense in the Chinese sporting world whether it was Overseas Chinese travelling to Nanjing or Shanghai to participate in the

\footnotetext{
${ }^{39}$ Purcell, The Chinese in Southeast Asia, pp. 299-300.

${ }^{40}$ Purcell also describes Chinese nationalism in the Dutch Indies during this period (ibid., pp. $448-50,466-67)$.

${ }^{41}$ For later examples of this type of imagined Greater China, see 1950s-era "maps" of a Qing Dynasty that covered all of continental Southeast Asia in Stephen Uhalley Jr., "'Greater China': The Contest of a Term", Positions 2,2 (1994): 277-78.

${ }^{42+} \mathrm{Di}$ ba jie Yuandong yundong dahui zhi xiansheng" [Welcoming the Eighth Far Eastern Championship Games], Jiaoyu zazhi (The Educational Review) 19,7 (1927): 9.

${ }^{43}$ "What's What in the Sporting World", Tiyu (Physical Education) 1.2 (1927): 33.

${ }^{44}$ This likewise was true of the Honolulu Chinese baseball team, who came back to represent China in the 1927. Far Eastern Championship Games after a twelve-year absence.
} 
National Games, or even (as in the case of several soccer players from Singapore and the Indies) joining the ROC Olympic team in 1936.

Assumptions about the loyalties of these Overseas Chinese athletes were so airtight that the Tenth Far Eastern Championships, held in Manila in 1934 and joined by the Dutch East Indies for the first time, created a substantial crisis in the Chinese sporting world. The Indies soccer team included five ethnic Chinese players, leading one Chinese observer to remark, "They are talent from our nation being employed by another (Chu cai Jin yong, literally "talent of the Chu kingdom being employed by the Jin") - what a pity that they cannot fight for glory for the nation!"45 This author used the same frustrated phrase to describe Kho Sin-kie, another Javanese Chinese tennis star who represented the Indies at these same games. ${ }^{46}$ The details of Kho's case, however, made his "betrayal" of the Chinese nation even more serious. Kho, representing the Indies Chinese population, had captured the men's tennis championship at the 1933 National Games in Nanjing. Representing his Java home in an unquestionably "national" Chinese setting like this was clearly acceptable; after all, the long trips that these Overseas athletes made to reach China's spiritual centre seemed to make their loyalties to China crystalclear. ${ }^{47}$ But this picture became frighteningly cloudy when Kho chose to represent the Dutch East Indies, and not a Chinese motherland, at Manila. ${ }^{48}$

These Manila Games seemed to portend both the best and worst for those who dreamed of a strong Greater Chinese presence in Asia. When the ROC delegation arrived in Manila, they were honoured by a tremendous welcome at Pier Seven by some seven or eight thousand members of the local Chinese population. The giddy Chinese observer quoted above wrote that "the activity and human tide seemed to set the entire structure of the great pier itself in motion"; a procession of more than 200 cars paraded the athletes through the Manila streets in "the warmest welcome these skies have ever seen". 49 But the Kho problem threatened to saddle even joyous spirits with doubts about this Greater Chinese essence. First was the troubling question of whether Kho's loyalties to a physical or literal home outweighed those to some ancestral or racial Chinese motherland. Secondly, his choice to represent the Dutch East Indies and not the ROC seemed to confirm the worst Chinese nightmares of "sheets of loose sand" and a China not truly united in the face of foreign (sporting or warring) threats.

Kho simply defied the modern "Huaqiao" (overseas Chinese sojourner) label that the Chinese sporting community would have assigned him. Though ethnically "Hua" (Chinese), Kho punctuated his "qiao" sojourn according to personal, not national, dictates. And his later career, if viewed through nationalist lenses, is even more incomprehensible. Kho

\footnotetext{
${ }^{45}$ You Yinzu, "Yuanyun qianjing (Ma-ni-la tongxin)" [A Far Eastern Games preview (Letter from Manila)], Renyan zhoukan 16 (1934): 323.

${ }^{46}$ Ibid., p. 323.

${ }^{47}$ Still, those Huaqiao, like tennis stars Khoo and Lum, who represented the more authentically Chinese locales of Shanghai and Sichuan at the National Games, were surely appreciated that much more. Cai Yangwu, "Jiu Zhongguo wangtan san wei Huaqiao qiuxing" [Three Overseas Chinese stars of the Old Chinese tennis world], Tiyu wenshi 37 (1989): 33.

${ }^{48}$ In contrast, Kho's fellow Javanese Chinese tennis star Khoo Hooi-hye represented China in these Far Eastern Championships.

${ }^{49}$ You Yinzu, "Yuanyun qianjing", p. 324.
} 
went on to represent China in several Davis Cup competitions between 1935 and 1946 , played in three Wimbledon tournaments, and captured British clay court national titles in $1938-39 .^{50}$ To a present-day historian, Kho's career can very well serve as a textbook example of how fluid and shifting cultural identities can be. Yet to his contemporary sporting public in China, the unsettling lack of Chinese loyalty exhibited by Kho and others like him ${ }^{51}$ must have made this sporting enterprise seem a much less trustworthy route toward Chinese solidarity and strength.

Another common, yet similarly ambiguous, way in which connections between China and the Nanyang Chinese were forged was via the flood of athletic teams which embarked on sporting tours of Southeast Asia. These teams could range from squads representing a single (and well-endowed) Shanghai or Nanjing school to entire Olympic delegations. During the decade from 1927-36, at least twenty Chinese semi-professional, scholastic and national sports teams enjoyed Southeast Asian tours. ${ }^{52}$ Several teams also toured Japan and Korea during this time as well, but Nanyang was the destination of choice for these representatives of the Chinese sporting project. Such tours were seen as a way of bringing Chinese and Overseas Chinese together in healthy and "righteous" competition. They were designed to teach Chinese athletes about this remarkable Overseas China, while reacquainting the Huaqiao with the heartiest and healthiest representatives of the true Chinese nation. However, these competitions could still pose similarly vexing problems for those involved and their conceptions of a united Greater China.

Such outings could be very cathartic experiences for both the ROC teams and the local ethnic Chinese living in colonial settings. In 1929, the Java Chinese Soccer Association invited Shanghai's famed China Joy Soccer Club to the Indies for a twelve-game tour. Yu Hengzhi, who coached the China Joy team, remembers the locals being electrified by the Shanghai squad's undefeated run through this schedule. They reportedly took to China Joy's star \#9 Lee Wai-tong, the country's "King of Soccer", so thoroughly that a new "\#9" marketing craze was born in the Chinese community there. ${ }^{53}$ With the benefit of fifty years' hindsight, Coach Yu in 1982 recalled the Indies Chinese population's enthusiastic response as a direct challenge to Dutch colonial rule that worked to exclude their political participation. ${ }^{54}$ It is easy to imagine the satisfaction of the China Joy players and their fans at this successful demonstration of Chinese strength and teamwork

${ }^{50}$ Cai Yangwu, "Jiu Zhongguo wangtan", pp. 33-34.

${ }^{51}$ Chen Jian, a Malayan Chinese sprinter, was the first woman to appear in three Chinese National Games. However, her similarly chequered past - running for Fujian (her ancestral home) in 1930, Shanghai (where she studied at the East Asian P.E. School) in 1933, and the Malayan Chinese team in 1935 - also made Chen a liminal figure in the sporting world. Quanguo milyundongyuan mingjiang $l u$ [Roll of the nation's women athletes] (Shanghai: Qinfen shuju, 1936), p. 11.

${ }^{52}$ The summer of 1933, only months before the triumphant Fifth National Games held in Nanjing on 10-20 October, was the busiest time for Chinese teams plying these ancient routes. That summer, Shanghai's East China (Donghua) Soccer Club toured the Philippines, the Fudan University volleyball team made a trip to Southeast Asia, the Shanghai Southern Commercial Institute track and field team traveled to Manila, and the Fujian Provincial men's and women's basketball teams concluded a tour of Malaya and Singapore, the women's team returning to China an undefeated 17-0.

${ }^{53}$ Yu Hengzhi, "Nanwang de Lehua zuqiudui" [The unforgettable China Joy Soccer Club]. Shanghai tiyu shihua 2 (1982): 12-13.

${ }^{54}$ Ibid., p. 13. 
right under the noses of the European colonial power. However, soccer is obviously about winners and losers, and one also can imagine the great ambivalence felt by both Republican and Nanyang Chinese about these one-sided competitions. Pre- and post-game socializing aside, the heat of these competitions likely left little room for romantic pan-Chinese solidarity. The official policy described above of including Overseas Chinese representatives on ROC teams clearly could present solid examples of true Greater Chinese teamwork. But these tours, almost all private initiatives, seemed to provide for situations that could be as liminal and awkward as they were encouraging and inspirational.

One of the more celebrated trips was that made by the Nanjing Central Martial Arts \& Physical Education Institute's martial arts and basketball teams to Singapore, several other Malayan cities and Manila in 1936. This tour was funded in large part by two of Singapore's Chinese business giants, the shipping and rubber tycoon Tan Kah Kee and the "Tiger Balm King" Aw Boon Haw, who also donated great sums of money to the Nanjing Institute itself. The three-month voyage was designed to allow the Institute's eighteen-man delegation to teach and learn much about Greater Chinese traditions, values and aspirations. ${ }^{55}$ The balance between martial arts and basketball is also very revealing, in terms of the well-rounded image the Nanjing state hoped to cultivate; these fine tiyu specimens sent along to Southeast Asia would represent to the Chinese communities there the Republic's mastery of both the particular Chinese and universally-defined modern forms. The basketball team's $45-0-2$ run and the guoshu squad's sixty-five sparkling demonstrations likely proved to many these Nanjing representatives' worth as a unit embodying all that was good and strong about the modern Chinese nation and people. However, some moments recorded by these participants also allow us to see things that complicated their notions of this oppressed yet loyal Overseas China.

In Singapore, the Institute representatives visited the Aw family's private Tiger-Panther Swimming Pool, and were simply amazed by a sign on the outside fence which read, "Only Chinese allowed inside to swim". ${ }^{56}$ The Nanjing basketball and martial arts stars saw themselves bringing true modern Chinese essences to Nanyang; how could these sojourners, living as they did in the very belly of the imperialist beast, manage to be even more patriotic and Sino-centric than "real" Chinese?

The Nanjing group's audience with a Malayan ruler in Kuala Lumpur also left the athletes stunned. Three of these participants remembered the ruler being shadowed by, and taking orders on the smallest matters from, a British officer - a situation that made the Chinese group "extremely infuriated, in the true spirit of 'Give me liberty or give me death"'.57 This power imbalance provided a jarring reflection of the fate of an "extinct nation", a fate into which Chinese prayed they would not follow these South Seas kingdoms. Events like these also complicated the Nanjing athletes' understanding of the complex and challenging environment in which Nanyang Chinese thrived and surely challenged their preconceptions about the "Huaqiao" world. The sporting connections forged between China and Nanyang in the 1930 s were based chiefly on these nation-state-friendly norms

\footnotetext{
${ }^{55}$ Pang Yusen, Li Zhenzhong and Tang Baokun, "Nanjing Zhongyang Guoshu Tiyu Zhuanke Xuexiao Nanyang lüxingtuan chufang zhuiji" [Recollections of the Nanjing Central Martial Arts and Physical Education Institute trip to the South Seas], Jiangsu tiyu wenshi 3 (1985): 31-34.

${ }^{56}$ Ibid., p. 32.

${ }^{57}$ Ibid., p. 33.
} 
of competition and fair play. But the confusing contacts that such tours provided to Greater China dreamers like the Nanjing delegation could hardly have reassured them that a new imperium in imperio lay in the Republic's near future. These sporting forms were designed for interaction between sovereign nation-states of self-conscious and healthy citizens. Yet the devilish details that many ROC athletes learned about the Nanyang Chinese world could only have posed a frustrating challenge to those who saw these sporting forms and values as the answer to the Greater Chinese question.

If these notions of a Greater China united via the world of sports could become vague and complicated and downright contradictory, there was still one dimension of the relationship that truly could maintain new ties between China and its Overseas subjects - business. Commerce, an arena into which Overseas Chinese had never feared to tread, connected to modern tiyu in a myriad of ways, from advertising and the growing sporting goods industry to the very capitalist ideals that formed the basis of the new sporting culture. And these were the transnational Chinese connections that seemed to flow most easily from these sporting ties between China and its "Huaqiao".

Wang Huaiqi, the famed Jiangsu native physical education expert who turned out fiftynine books on physical education during the $1910 \mathrm{~s}-20 \mathrm{~s}$, published one title in 1928 on the topic of "starball" (xingqiu 星球), a miniaturized form of soccer supposedly more suitable for women and children. Along with his detailed explanations of the background and rules of the game, his book also included several direct plugs for the sporting goods division of the Tan Kah Kee Corporation. ${ }^{58}$ Tan, the Singapore-based Chinese industrialist mentioned above, was no stranger to this world of Greater Chinese tiyu. He was a strong advocate of physical education programmes at Xiamen University and the Gathered Beauty School, both products of his philanthropy in his Xiamen home, ${ }^{59}$ and had led the South Fujian Martial Arts Squad on fund-raising tours of Malaya in 1929 and 1930. While Tan donated considerable amounts to these modern physical culture efforts, he likely was also determined to earn at least some of it back via the sporting goods trade. His eponymous corporation manufactured high-quality leather starballs for the Chinese market; though made in Malaya, they were proudly stamped with a "National Products" (Guohuo 国货) seal. By the late 1920s, this popular method of associating ethnic Chinese business enterprise overseas with the nationalist movement inside the Republic was simply too well-proven for a seasoned and patriotic businessman like Tan to ignore.

In this context, the Guomindang-era sporting enterprise shares much in common with aspects of the Pure Martial expansion into Southeast Asia. There were many profits to be had by the slick businessmen who wisely jumped aboard any tiyu bandwagon, be it

${ }^{58}$ Wang Huaiqi, Xingqiu guize [Starball Regulations] (Shanghai: Zhongguo jianxue she, 1928), front cover and pp. 6-16. These commercial plugs do not constitute the full extent of Wang's obsession with the capitalist nature of modern physical culture; some of his musings on the ties between modern tiyu and capitalist labor discipline are almost downright chilling. One passage of Wang's went, "[A]thletes' rules-respecting participation in sports is just like the work done by laborers to produce goods.... [T] [Tere is also the matter of athletes' respect for the rules. Whether in defeat or victory, there will always be some violation of the rules. Again, how much does this resemble the factory discipline that all must follow?" (pp. 57-59).

${ }^{59}$ James A. Cook, "Bridges to Modernity: Xiamen, Overseas Chinese and Southeast Coastal Modernization, 1843-1937" (Ph. D. diss., University of California, San Diego, 1998), pp. 202-203. 
martial arts or the modern sporting culture. It is here, in the business world, that Greater China could finally mean something tangible. Only in the centuries-old world of transnational Chinese trade could this concept be freed from the vague dreams of those who wished to define it in cultural terms or those expansive nationalists who impracticably expected to incorporate Southeast Asian lands into a territorially-defined Greater China.

Those like Wang and Tan who were involved in these Nanyang Chinese sporting (and other) business dealings, did not need either of these visions of "Greater China"; they had exactly the transnational Chinese community they wanted. Any perusal of sporting magazines from the late 1920 s and 1930 s makes it clear how important the Southeast Asian connection was for this sporting industry. Singapore's May May Company advertised their badminton, ping-pong, tennis, basketball and soccer products in the pages of Shanghai's The Young Companion. The Nanjing Branch of the Baoding Lucky Labor Factory carried tennis rackets and strings made in Singapore. A friendly write-up on Shanghai's famed Victorious Student Sporting Goods Factory in the pages of The Chin Fen Sports Monthly mentioned their recent expansion into the Singapore sporting market with a local branch of their own. ${ }^{60}$

The enthusiasm for modern tiyu that many of these Southeast Asian Chinese businessmen shared made perfect sense for the transnational commerce networks they worked so hard to cultivate between their colonial homes and the Republic. As with the Pure Martial Association, the ethnic Chinese of Nanyang were more than willing to support enterprises that brought glory to the Chinese people of all nations. In 1936 and 1948, when the Republican government proved unable to commit the great sums needed to send ROC delegations to the Berlin and London Olympic Games respectively, the Chinese of Southeast Asia came to the Olympians' financial rescue. In 1936, the Chinese soccer team played an Olympic fund-raiser exhibition schedule of twenty-seven games in sixty-two days before appreciative and generous Chinese crowds in Vietnam, Singapore, the Indies, Burma, Malaya and Siam, before meeting the rest of the Olympic team in Bangkok. ${ }^{61}$

Yet these notions of a "Greater China", these seemingly straightforward connections between Huaqiao green and Chinese dreams of Olympic gold, were simply useless in the face of KMT-style politics and nationalism. In 1948, when the Chinese Olympic Committee asked prominent Overseas Chinese to donate to the Olympic cause, Aw Boon Haw delivered specific conditions to supplement his generous offer. His son Aw Haw, negotiating the contribution in Shanghai, proposed that all twelve members of his father's Singapore Soccer

${ }^{60}$ Liangyou (The Young Companion) 40 (1929): 7; Tiyu zarhi 1,1 (1935): 97; Zhao Wu, "Lisheng gongchang jishi" [The story of the Victorious Student Factory], Qinfen tiyu yuebao (The Chin Fen Sports Monthly) 4,3 (1936): 205.

${ }^{61}$ Chuxi Di shiyi jie Shijie yundonghui, Section 1, pp. 2, 8-9, 17-18; interview with Cheng Jinguan, Suzhou, China, 2 March 1997; Morris, "Cultivating the National Body", pp. 413-15. The rest of the Olympic delegation, on board the Italian Conte Verde, made stops in Hong Kong, Singapore, Kuala Lumpur, Bangkok and Bombay, each stop bringing fabulous welcomes from the local Chinese population. In Singapore, more than 1000 Overseas Chinese greeted the team, taking the Olympians in ten cars on a tour of the city and then to a banquet hosted by ROC Consul Diao Zuoqian. Huge crowds also attended a basketball scrimmage between the Chinese Olympians and the Singapore All-Stars, which was followed by a demonstration by the nine-person Olympic martial arts team. See Chuxi Di shiyi jie Shijie yundonghui, Section 1. pp. 18-19. 
Club be named to the eighteen-man Chinese national team! Naturally, these un-national conditions were too much even for the cash-starved Olympic Committee. The Tiger Balm King's second request, that the younger Aw be able to accompany the Olympic delegation as an "official advisor", proved more acceptable. ${ }^{62} \mathrm{But}$ it would have been clear to all involved that this sporting Greater China - even with the sacred national cause of Olympic gold at stake - might never prove to be what they had imagined. Overseas Chinese support of the Republican sporting enterprise could find a broad base in ethnic pride. But the nationalism conceived by Guomindang planners and bureaucrats in China was totally foreign to these Nanyang Chinese. Their Greater China was characterized not by territorial nationalism, but by a simple economy, one that may even have seemed unthinkably crass or even apostate by the dictates of official Chinese state nationalism.

Official Guomindang dreams of a Greater China that could be founded in part in the ideologies and values of modern sport allowed new types of engagement between ROC residents and Overseas Chinese during the Nanjing Decade. The KMT's vigorous partystate was able to provide for more of this contact than ever before and to authenticate it with an official new Greater Chinese ideology of the robust "nation-race" (minzu). Where tiyu ties in the 1920 s had been limited to cultural exchanges via an essential Chinese martial arts, the Guomindang era brought a new emphasis on the competitive sports and their unshakeable position in the new modern nation-state order. These sporting forms were perfectly effective in connoting the real world struggles between sovereign nations. However, they ended up providing much less ground from which to reach for the tantalizing dreams of a Greater China that knew no worldly boundaries.

\section{The Postwar Period and the 1948 Seventh National Games}

In 1948, the Republic of China held its last National Games, an affair kicked off by a dramatic torch relay covering the 236 miles between Nanjing and the Games site at Shanghai. This festival, which marked the reunification of China, was to be an important step in reminding Chinese of the immensity of their recent victory over Japanese imperialism, and of the glory of the Republic now "ruling" over its greatest geographical expanse ever. As one observer wrote,

Now our bondage has finally been cast off. We see Taiwan athletes taking part in the National Games for the first time. Those in the Northeastern provinces and cities, even amidst the fires and chaos of [civil] war, do not fear danger, and all have sent teams

\footnotetext{
${ }^{62} \mathrm{Aw}$ Haw clearly had other non-Olympic goals in mind during his 1948 visits to Shanghai. That September, Chiang Kai-shek's son Ching-kuo, in charge of implementing his father's Financial and Economic Emergency Measures in Shanghai, ordered Aw's arrest for smuggling gold and foreign currency. Aw quickly fled to Hong Kong, evading arrest but also forfeiting his short-lived Olympic legacy. Lloyd E. Eastman, Seeds of Destruction: Nationalist China in War and Revolution 19371949 (Stanford: Stanford University Press, 1984), pp. 186, 267. On a related note, a supposed donation from Philippine Huagiao (but later found to be a fabrication by Chinese Olympic Committee Chairman Hao Gengsheng in order to maximize his influence during this planning period) was the deciding factor in ensuring that an Olympic team could be sent to London. In the end, the Olympic basketball and soccer teams (the former featuring three Huaqiao players on its 10-man roster) still had to make a draining pre-Games tour of Saigon, Manila, Bangkok, Singapore, Rangoon and Calcutta to raise one last cache of badly-needed funds. Dong Shouyi, "Aolinpike yu Zhongguo" [The Olympics and China], in Ji Hongmin, Yu Xingmao and Lü Changfu, eds., Aoyunhui yu Zhongguo [The Olympics and China] (Beijing: Wenshi ziliao chubanshe, 1985), pp. 30-31.
} 
over land and water, from beyond the passes and mountains. Overseas Chinese athletes, and teams from border provinces like Xinjiang, Xikang and Qinghai, all have made long treks to these Games. It is this kind of fervent and enthusiastic emotion that allows us to feel the solid cohesion and the great ties of intimacy that exist amongst those of the Chinese nation-race (minzu) ${ }^{63}$

This formulation of the empowered and emboldened minzu obviously left little that distinguished Nanyang Chinese from other Chinese travelling to Shanghai from distant Republican lands. The renewal of the National Games after a thirteen-year hiatus would thus continue, over greater expanses, older themes of the Games as a means of uniting China's fittest men and women in one glorious celebration of the strong Chinese nationrace. These Games would also prove to be a last grandiose gasp for the KMT party-state, with regard both to the world of sporting culture in China and to its position at the centre of a united Greater China.

On the surface, there was much about which to be excited at these Seventh National Games. Participation was quite impressive, with teams coming to Shanghai to represent twenty-nine provinces, thirteen municipalities, the four branches of the military, and even the nation's police. These ROC delegations also were joined by teams representing seven "Huaqiao" populations - Indonesia, the Philippines, Malaya, Saigon, Siam, Toronto, and Honolulu - by far the greatest Overseas Chinese presence at any National Games. (The Fifth and Sixth Games, held in 1933 and 1935 respectively, had included only a handful of Indies and Malayan Chinese athletes.) This "Huaqiao" participation in the Chinese National Games now was also routinized through a new Overseas Chinese Athletic Federation. ${ }^{64}$

Adding to the excitement, an estimated average of 65,000 people a day ventured from the city proper out to the modem Shanghai Stadium in the Jiangwan suburbs for the meet. ${ }^{65}$ The Games schedule featured the richest selection of competitions ever for these athletes, with new events like ping-pong, wrestling, weightlifting and Western-style boxing pushing the total to eleven men's and eight women's events. ${ }^{66}$ The media also reported endlessly on the new technologies - from the Shanghai news leader Shenbao's own high-tech Games headquarters, to the airplanes used to transport athletes to Shanghai from Xinjiang or Southeast Asia, which were being utilized and shown off at these games.

Many looked to the Nanyang Chinese representatives to provide a special spark at these Games. Famed Huaqiao sports figure Chen Zhang'e, ${ }^{67}$ in an essay written for the

${ }^{63}$ Chen Xunyu, "Ganxiang yu xiwang" [Emotions and hopes], in Di qi jie quanguo yundonghui huakan [Seventh National Games Official Pictorial] (Shanghai: Shenbaoguan, 1948), p. 1.

${ }^{64}$ Wang Zhenya, Jiu Zhongguo tiyu jianwen [Glimpses of physical culture in the old China] (Beijing: Renmin tiyu chubanshe, 1987), pp. 7-8.

${ }^{65}$ Di qi jie quanguo yundonghui huakan, p. 61.

${ }^{66}$ The schedule also included nine demonstration events: men's and women's archery, Chinese boxing (quanshu, formerly an official competition in the days when guoshu was still a mationally significant form), badminton, men's gymnastics, diving, water polo, baseball, racewalking, and mini-soccer. Di qi jie quanguo yundonghui zhixu ce [Official program of the Seventh Nationa] Games] (Shanghai, 1948), pp. 103-117.

${ }^{67}$ As a young man, Chen had been a nationally-known track star based in Xiamen. There, in 1920 he ran a race against a train; his reputation soared after he defeated the train and proved the human body's capacity to better even this ultimate symbol of modernity and commerce. Gu Xin, "Tiyujia Chen Zhang'e" [Physical education expert Chen Zhang'e], p. 48. (This article from an unknown source was kindly provided by James Cook.) 
Philippine basketball team, assigned them four important "missions": (1) Bear the glory of representing the 120,000 Overseas Chinese; (2) use the arts of basketball to better yourselves through these contacts with others; (3) make an emotional connection with the domestic residents of our nation (woguonei renshi 我国内人士); and (4) spread the word of our Overseas Chinese sporting spirit. ${ }^{68}$

In many ways these Nanyang Chinese athletes seemed to embody the best of Chinese sporting traditions. Shenbao's sportswriters "selected one player as a perfect model of sportsmanship, Siam's Li Mujin, who always obeyed the referees". Li's media aficionados went on to elaborate, "Even when he was called for a foul he would shake hands with, and apologize to, the player he fouled. This type of courageous and tolerant spirit is well worth admiring." ${ }^{199}$ Another glory showered on Overseas Chinese athletes was the invitation given the 31-member Saigon delegation to travel to Nanjing to meet Chiang Kai-shek and congratulate him on his recent presidential election victory. ${ }^{70}$

Yet the exoticized terms in which many of these natives of the South Seas were described gives one pause as to where exactly they could possibly have fit in a new Chinese order. One of the stars of the Games was Malayan Chinese swimmer Feng Zhaoyu, about whom it was written, "Of all the male swimmers, he is the most healthy and beautiful (jianmei 健美). His skin is completely palm-black in colour, his body is covered with light hair, his muscles are full and supple, and he is just 19 years old." The attractive Malayan Chinese women swimmers Tan Jinliu and Huang Bixia were photographed endlessly in their bathing suits, their photos captioned simply "Malai Meirenyu" (马来美人鱼, lit. "The Malay Mermaids"). ${ }^{72}$ This term of Malayan ethnicity - not Malayan nationality - indicated just how exotic and different these tanned Nanyang athletes seemed to be.

An article on the track and field standouts at these Games included the passage, "Chen Yinglang is known as the 'track and field wonder' in Taiwan, and [Malayan Chinese] Huang Liangzheng is also quite famous in Southeast Asia. They do not speak Mandarin Chinese very well, but they are very well-built." ${ }^{\text {73 }}$ Taking these imaginations of the exotic South Seas Chinese one step further, a writer reporting on the Siam-Police men's basketball game used curiously anthropological terminology to describe as "native songs and dances" (tufeng gewu 土风歌舞) the fight songs chanted on the sidelines by members of the Siamese Chinese soccer team. ${ }^{74}$

The presence of the Taiwanese athletes at these Games was jarring in itself; their darker skin tones, laughable Mandarin skills, and reputed history of slavishness to their Japanese colonial masters simply repulsed many of Shanghai's proper and cosmopolitan

${ }^{68}$ Chen Zhang'e, Tiyu mantan [Informal conversations on sport] (Shanghai: Dongnan chubanshe, 1948), p. 4.

${ }^{69}$ Di qi jie quanguo yundonghui huakan, p. 28.

${ }^{70 " X i g o n g ~ x u a n s h o u t u a n ~ j i n y e ~ Z h u x i " ~[S a i g o n ~ d e l e g a t i o n ~ c a l l s ~ o n ~ t h e ~ C h a i r m a n], ~ Z h e n g y a n b a o, ~}$ "Quanyun tekan" [National Games Special Publication], 12 May 1948, p. 1.

${ }^{7}$ Di qi jie quanguo yundonghui huakan, p. 10.

${ }^{72}$ Ibid., p. 14; Zhengyanbao, "Quanyun tekan", 11 May 1948, p. 4. "Malay" is clearly used here as a geographic rather than an ethnic term.

${ }^{73}$ Di qi jie quanguo yundonghui huakan, p. 38.

${ }^{74}$ Moming, "Lanqiu quanri zhancheng" [Basketball scores from the entire day], Zhengyanbao, "Quanyun tekan", 7 May 1948, p. 2. 
Chinese. ${ }^{75}$ Even more problematic, though, were the Nanyang Chinese and their very different appearances, accented speech and potentially messy political backgrounds which all made it easy to categorize them as another not-quite-truly-Chinese group. This exoticization of Nanyang Chinese is not a phenomenon new or unique to the 1940 s postwar period. Periodicals from the 1920s, like Shanghai's The Young Companion, regularly featured beefcake shots of flexing shirtless Nanyang Chinese strongmen. ${ }^{76}$ Swimming had also long been considered a somewhat exotic sport; one writer in 1925 had to concede that unlike natives of the Philippine and Japanese island nations, "the Chinese mainland population are just not born with swimming abilities".?7

Yet this categorization extended past the exoticizing treatment of individual Nanyang Chinese swimmers and other athletes. This common understanding of Nanyang Chinese people's marginalized and categorized position in a new Chinese order helps us define the limits of an imagined Greater China that could be united on the playing fields of Shanghai and Nanjing. Guomindang ideologues of the state's sporting apparatus found very logical the visions of the "enthusiastic ... cohesive ... intimate" Chinese nation-race which they articulated. These Greater China dreams, however, were plagued by two logical fallacies. First was the assumption that Nanyang Chinese participation in a Chinese National Games somehow guaranteed that "Chineseness" was the sum total of this group's self-identities. The second was the conjecture that Nanyang Chinese with "Chineseness" as the sum total of their self-identity would naturally choose a Nanjing-centered Guomindang-ruled Republic as the vehicle of these nationalist designs.

Obviously, we now know the problem with the first assumption - that being Chinese was merely one aspect of Nanyang Chinese identities complicated by issues of race, class and politics likely foreign to almost any Republican Chinese. And the absurdities of the second hardly merit space here. But even assuming that the Nanyang Chinese shared these dreams of a sporting Greater China, there were just too many differences and too many suspicions - racial, cultural, political, linguistic - on the part of ROC Chinese for such a Greater China to come together in this realm.

\section{Conclusion}

By the 1920 s, modern physical culture was already an important ingredient of Republican-era designs for a strong and worthy Chinese nation-state. Here I have discussed how these notions of a fit and healthy China also figured prominently in Chinese imaginations of a Greater China that might transcend political boundaries and reach the

\footnotetext{
${ }^{75}$ One author explained the Taiwanese athletes' surprising successes in the Games by pointing out that they were naturally obedient "slaves" who had been trained well by the Japanese colonial regime. "Xuanshou jianying" [Athlete shorts], Zhengyambao, "Quanyun tekan", 5 May 1948, p. 4; Tong Xiangzhao, "Cong Taiwan xuanshou tanqi" [Talking about the Taiwan athletes], Zhengyanbao, "Quanyun tekan", 11 May 1948, p. 4.

${ }^{76}$ For example, see Liangyou (The Young Companion) 34 (January 1929), p. 22; Liangyou (The Young Companion) 47 (1930): 24.

77 Jiang Xiangqing, "Yuandong yundonghui gaikuang" [On the Far Eastern Championship Games], in Di qi jie Yuandong yundonghui quanguo yuxuan dahui tekan [Special publication of the National Selection Meet for the Seventh Far Eastern Championship Games] (Shanghai: Di qi jie Yuandong yundonghui quanguo yuxuan dahui tekanshe, 1925), p. 44.
} 
waiting embraces of Overseas Chinese all over the world, especially in the colonies of Southeast Asia. The forms understood to provide these pan-Chinese sporting ties, however, had very different implications for visions of a greater China.

In the early 1920s, many could imagine China and Nanyang Chinese as bound together by "traditional" and essential cultural ties, like those embodied in the Pure Martial arts, which knew no modern borders. By the Nanjing Decade, the team sports, which now were thought to serve as the basis of this Greater China, assumed the very forms of competition and fair play that shaped the new twentieth-century nation-state order. The former proved to be an acceptable and practical way for Nanyang Chinese to maintain that "Chinese" aspect of their identities by participating in supposedly ancient and aggressive arts, which, with each kick and punch, allowed the martial artist to feel what it meant to be Chinese. Once Greater Chinese dreamers departed from these feel-good abstractions, however, efforts to "re"-integrate Nanyang communities into a new Chinese order as Huaqiao through competitive sport could never quite recapture the magic of the Pure Martial's decade of dominance in the 1920s.

One type of Greater Chinese community, forged via the age-old commercial connections between the Republic and Southeast Asia's Chinese sojourners, could still flourish during this KMT period. Businessmen manufacturing or selling sporting goods, or sponsoring sports teams, became an important source of legitimacy for this transnational Chinese tiyu activity at the same time that they could reap great profits from this new sporting community. Besides these captains of commerce and industry, however, the Guomindang's sporting programmes were useless in terms of creating the powerful and coherent Greater Chinese community of which so many dreamed. Nanyang Chinese identities were too vague, Republican Chinese expectations too unrealistically one-dimensional, and these sporting forms simply too deeply implicated in modern nation-state formulas, for this great sporting enterprise to create any meaningful bridge between the Republic and the ethnic Chinese of the South Seas. 